\title{
Loeffler's syndrome: A type of eosinophilic pneumonia mimicking community-acquired pneumonia and asthma that arises from Ascaris lumbricoides in a child
}

\author{
(D) Oner Ozdemir \\ Division of Allergy and Immunology, Department of Pediatrics, Sakarya University Training and Research Hospital, Sakarya, Turkey
}

Cite this article as: Ozdemir O. Loeffer's syndrome: A type of eosinophilic pneumonia mimicking community-acquired pneumonia and asthma that arises from Ascaris lumbricoides in a child. North Clin Istanb2020;7(5):506-507.

$\mathrm{H}$ ere, we describe a patient with Loeffler's syndrome initiated by Ascaris lumbricoides, who mimicked the clinical picture of community-acquired pneumonia (CAP) and bronchial asthma. A 5-year-old male child was presented to an outside center with complaints of cough, dyspnea, wheezing, intermittent fever for three days. He was diagnosed with pneumonia after physical and radiological evaluations then admitted for treatment at an outside hospital. After discharge, his symptoms

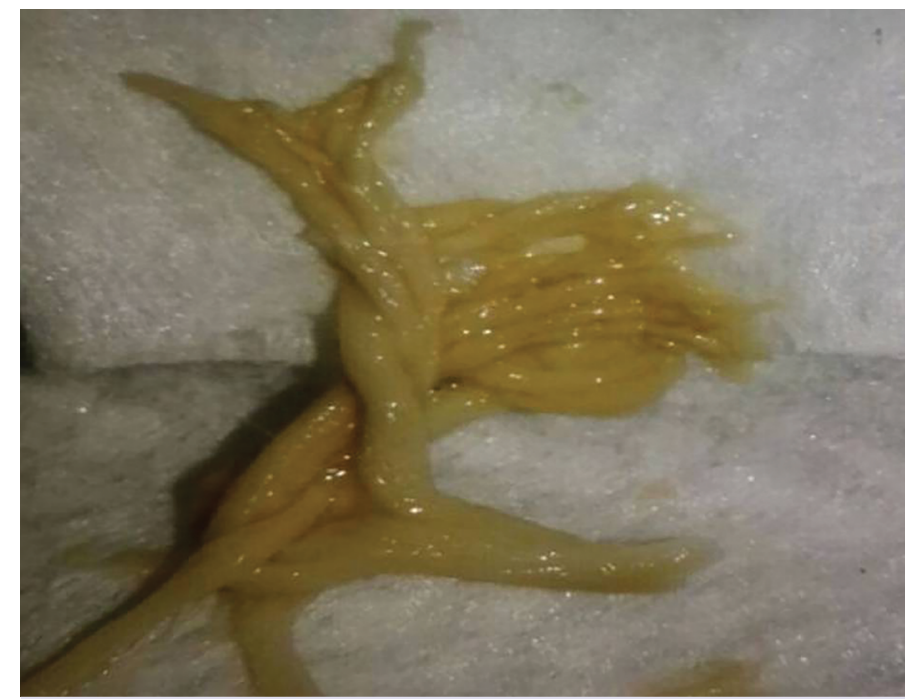

FIGURE 1. The most common intestinal parasite (worm, Ascaris) in humans is seen after coughed up by the patient. decreased but persisted for several weeks and coughed a substance up by sputum expectoration (Fig. 1). When he presented to us, he seemed to be in a good general condition, but his physical exam revealed coarse polyphonic rhonchi, especially on the upper zone of the left lung. Evaluation of the peripheral blood smear of the patient demonstrated mounting eosinophilia (from $0.2 \%$ to $2.06 \%-338 / \mathrm{mm}^{3}-$ ), while $\mathrm{IgE}$ was $50 \mathrm{IU} / \mathrm{mL}$. A chest $\mathrm{X}$-ray demonstrated unilateral upper zone patchy consolidation (pneumonic infiltrations) of the left lung (Fig. 2A). Despite antibiotic therapy, consolidation was not resolved but almost completely vanished when he vomited the parasite up (Fig. 2B). Macroscopic evaluation of
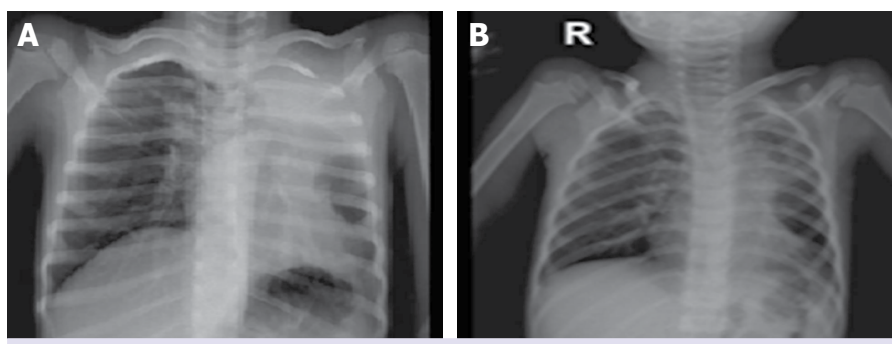

FIGURE 2. Pneumonia caused by the nematode Ascaris lumbricoides. Extraintestinal manifestations of ascariasis such as pulmonary ascariasis, "Loeffler's syndrome", are not common and can be misdiagnosed. Pneumonic infiltration at the upper lobe of the left lung $(\mathbf{A})$ is shown. The appearance of left lung (B) is seen after the patient coughed the worm up. 
the substance was confirmed as Ascaris lumbricoides by microbiologists.

The patient was diagnosed with Loeffler's syndrome, in which eosinophils gather in the pulmonary tissue in regards to a parasitic infection. Loeffler's syndrome should be thought early in the differential diagnosis for CAP and asthma, which is unresponsive to classic antibiotic therapy in individuals if they live in an endemic region for parasitic diseases in the developing countries $[1,2]$.
Informed Consent: Informed consent was obtained orally from the patient's father who participated in this report.

\section{REFERENCES}

1. Acar A, Oncül O, Cavuşlu S, Okutan O, Kartaloğlu Z. Case report: Löffler's syndrome due to Ascaris lumbricoides mimicking acute bacterial community-acquired pneumonia. Turkiye Parazitol Derg 2009;33:239-41.

2. Deveci U, Üstün C, Altınsoy HB, Akay A, Özdiller S, Aydın M. Loeffler's syndrome mimicking bronchial asthma and pneumonia in a child: case report. Turkiye Parazitol Derg 2013;37:288-91. [CrossRef] 